\title{
APEOESP E A MOBILIZAÇÃO DOS PROFESSORES PAULISTAS (1985 a 2000)
}

\author{
Antonio de Pádua Almeida ${ }^{1}$ \\ Vania Regina Boschetti ${ }^{2}$
}

\section{RESUMO}

$\mathrm{O}$ artigo discute a situação profissional e a organização sindical dos professores paulistas após 1985, tendo a escola pública como centro do debate. Destaca o trabalho da APEOESP enquanto entidade representativa dos professores, seu poder de mobilização, pautas de reivindicação e, suas estratégias de ação sindical. A pesquisa traz por referencial teórico as ideias de Libâneo e Saviani, ilustradas por textos documentais da entidade e publicações da imprensa cotidiana. Conclui reconhecendo que, apesar dos seus limites, o movimento sindical, tem atuação fundamental nas demandas em defesa da escola pública.

Palavras-chave: Escola Pública; APEOESP; Professores

\section{APEOESP AND SÃO PAULO TEACHERS MOBILIZATION}

\begin{abstract}
The article discusses the professional situation and the teacher's Union in São Paulo state after 1985, having public schools as the main issue of the debate. It points out APEOESP'S work as a teacher's representative association, its mobilization power, its lists of demands, as well as its Union actions strategies. The research adopts Libâneo and Saviani's ideas as theoretical reference; illustrated by documents from APEOESP and national press publications. The article concludes recognizing that, despite its limitations, the Union movement plays a fundamental role defending public schools.
\end{abstract}

Keywords: Public school; APEOESP; Teachers

O presente artigo $^{3}$ discute a situação profissional e a organização sindical do professorado paulista, no período logo após o término da ditadura civil-militar, frente às políticas governamentais implantadas, e suas divergências com o movimento sindical da categoria.

A partir de meados da década de 1980, com a volta do país ao estado de direito, a escola brasileira entrou numa etapa de reestruturação, inserindo-se no processo de redemocratização. A Constituição Federal de 1988 delegou à educação a responsabilidade de formar para a cidadania, visando à emancipação humana, corroborada em 1996, com a Lei de Diretrizes e Bases (LDB) em suas esferas: gestão, organização e postura dos professores em sala de aula.

Parte dos professores em exercício se formou e iniciou suas atividades docentes durante o regime militar, não adquirindo o hábito de participar de decisões coletivas e muitos levaram para as salas de aulas posturas autoritárias, presentes em sua formação. $\mathrm{O}$ governo militar, ao invés de valorizar a profissão docente pela exigência de boa formação acadêmica e por salários dignos, optara por amenizar o problema de forma superficial, ocasionando, de acordo com Ferreira Jr; (2006), a proletarização dos professores, arrochando seus salários e descaracterizando suas especializações. 
Um dos aspectos mais relevantes do processo de proletarização vivido pelo magistério brasileiro é que ele desmistificou as atividades pedagógicas do professor como ocupação especializada, pertencente ao campo dos chamados profissionais liberais, ocorrendo de forma acentuada, a paulatina perda do seu status social. A partir desse momento, teve início a construção da nova identidade social do profissional da educação submetido às mesmas contradições socioeconômicas que determinavam a existência material dos trabalhadores. (FERREIRA JR; BITTAR, 2006, p.1166/67).

As mudanças na educação durante o período militar, contribuíram para a construção de um outro perfil de professor. Na década de 1960, as escolas públicas eram referência de bom nível cultural. Os professores que vivenciaram esse período viram a transformação de uma escola que, privilegiou a quantidade e passou a generalizar-se com um trabalho obscurantista, que comportava apenas o aspecto burocrático enquanto o aspecto pedagógico era confinado e mutilado em sala de aula. Em duas décadas houve aumento quantitativo de escolas e professores, mas não houve aumento qualitativo.

Os professores formados nos cursos de licenciaturas curtas das faculdades privadas noturnas substituíram a pequena elite intelectualizada das poucas escolas públicas antes existentes. A extensão da escolaridade obrigatória de quatro para oito anos ocasionou a rápida expansão quantitativa da escola fundamental, exigindo, para o seu atendimento, a célere formação dos educadores, o que se deu de forma aligeirada. A combinação entre crescimento quantitativo, formação acelerada e arrocho salarial deteriorou ainda mais as condições de vida e de trabalho do professorado nacional do ensino básico, [...]. (FERREIRA JR; BITTAR, 2006, p. 1166).

No final da década de 1970 e início da década de 1980, quando os movimentos sociais e operários estavam emergindo, o professorado também teve uma atuação de destaque nas manifestações públicas e greves. Sua atuação foi igual a da maioria dos trabalhadores, lutando por melhores condições de vida e de trabalho, sem, no entanto (apesar da formação superior) ser, em sua maioria, uma classe detentora de consciência política intelectualizada, capaz de propor uma estrutura social contrária à exploração capitalista. $\mathrm{O}$ aspecto principal das lutas e greves ocorridas nesse período estava voltado para questões econômicas, visando corrigir a perda salarial e a consequente queda em seu padrão de vida. Alguns profissionais se destacaram e até se engajaram em movimentos políticos partidários, movimentos sindicais, da mesma forma que ocorreu com os operários fabris.

Premida pelo achatamento salarial e pela rápida queda no seu padrão de vida e de trabalho, a categoria profissional dos professores públicos de $1^{\circ}$ e $2^{\circ}$ graus foi desenvolvendo uma consciência política que a situava no âmago do mundo do trabalho, tal como já estava posta para a classe operária fabril. Em outros termos: incorporou a tradição da luta operária nos marcos da expressão sindical - e transfigurou-se numa categoria profissional capaz de converter as suas necessidades materiais de vida e de trabalho em propostas econômicas concretas. (FERREIRA JR; BITTAR, 2006, p. 1169). 
O poder de organização dos docentes enfrentou dificuldades. Apesar das mobilizações, greves e do enfrentamento à ditadura, o movimento sindical representativo da categoria teve limites para arregimentar número significativo de professores para participar das assembleias e dirigir suas ações. Isso começou a ser sentido no início da década de 1980, quando as convocações das lideranças sindicais gradativamente foram perdendo adesão e respostas para atividades coletivas do sindicato. A postura dos professores resulta, em parte, do não atendimento às reivindicações, pelo desgaste ocasionado pelas greves, frente à atitude governamental de autoritarismo e repúdio às mobilizações, além dos problemas sociais que as greves trazem às comunidades.

A constatação diante de acontecimentos negativos pode ser feita quando, a partir de 80, vai-se evidenciando um distanciamento do conjunto da categoria em relação às lideranças que há bem pouco tempo tinham sido reconhecidas. Poucos são os que passam a comparecer às manifestações públicas; poucos são os que atendem às convocações para assembléias regionais e/ou estaduais (tanto assim que em um dos Congressos de Professores é proposta uma diminuição no "quorum" necessário, sem o que se tornava impossível realizar uma assembléia que preenchesse as condições estatutárias), grande é a diferença do total de votantes nas eleições para a diretoria da APEOESP em 1979 (para mais) e nas eleições de 1981 (para bem menos) etc. Quando é buscada explicação para o afastamento e, mais ainda, quando é tentado o restabelecimento do vínculo e os resultados não vêm, uma questão se impõe à consciência dos líderes: Quem é o professor de hoje? (RIBEIRO, 1987, p. 280).

A delimitação temporal de 1985 a 2000 teve como elemento identificador o período de abertura política e a fase de transição rumo à democracia. E é sobre a ação dos profissionais que atuaram nessa época, que se analisa situação política e social do país nesse período. Para isso, importante comentar sobre a formação profissional docente identificada no âmbito de categoria profissional. Pode-se afirmar que o professorado se constituiu em grande contingente profissional, mal remunerado e, em grande parte, mal formado profissionalmente e também politicamente, mas que adquiriu consciência de sua situação e conforme Ferreira (2006) aderiu à tradição de luta dos operários, lutando pela superação de suas dificuldades materiais, realizando greves e manifestações.

Apesar da dificuldade de organização dos professores enquanto categoria, os profissionais do Estado de São Paulo, juntamente com a Associação dos Professores do Ensino Oficial do Estado de São Paulo (APEOESP) ${ }^{4}$, realizaram várias manifestações e greves nesse período, (1985 a 2000) obtendo algumas conquistas e também amargando derrotas. A ação coletiva do professorado paulista se constituiu em uma demonstração de descontentamento com a política governamental para a educação, e do descaso com a questão salarial e esteve diretamente ligada à atuação da APEOESP, em todo o estado de São Paulo.

As greves causaram grande repercussão, pois criavam problemas para os estudantes e seus familiares e traziam à tona os problemas da educação, levando inclusive a imprensa a se manifestar através de reportagens e editoriais, como fez o Jornal Cruzeiro do Sul, de Sorocaba, SP, que no editorial do dia 25/04/1989, período em que aconteceu uma das mais longas greves do magistério paulista, analisou a situação dos professores, a postura do governo em relação às reivindicações, os problemas sociais ocasionados pela greve, chamando a atenção para a delicada situação em que se encontrava a educação pública. 
Há, porém, que se dar atenção a um prejuízo mais sério, que as crianças e as famílias vêm sofrendo, ao longo dos últimos anos, quer as atividades das escolas estejam se desenvolvendo em aparente normalidade, quer estejam suspensas por força de uma greve: é um prejuízo ocasionado pela perda de qualidade do ensino e pela formação, na escola, de um ambiente nada favorável ao desenvolvimento da criança e do adolescente.

A permanente insatisfação em que estão vivendo os professores, em decorrência dos maus salários que percebem do governo do Estado, tem muito a ver com esse clima pouco favorável ao processo de ensino/aprendizagem. (MAGISTÉRIO..., 1989, p. 02).

Para uma categoria profissional ampla e presente em todo o estado, entrar e manter a greve por longo período era muito difícil ${ }^{5}$. A APEOESP, organizava grande número de caravanas do interior para a capital, onde normalmente se realizavam as assembleias gerais. Além disso, as sub-sedes da entidade faziam as assembleias regionais. Essas greves protagonizadas pelos professores paulistas trouxeram à tona os problemas enfrentados pela educação e mostraram a capacidade de organização desses profissionais, que não aceitaram a desvalorização de suas atividades de forma passiva. A APEOESP, contava com dirigentes bem preparados politicamente e com grande capacidade de convencimento, características importantes para atuação sindical. Além disso, os professores sentiam o arrocho salarial a que estavam submetidos e viam na greve a única possibilidade de conseguir amenizar essa situação. Outros ainda, compartilhavam com seus pares e refletiam, direta e objetivamente, sobre as questões educativas mais amplas, como qualidade de ensino, organização das estruturas escolares, recursos materiais e pedagógicos para o exercício de uma prática educativa que realmente fosse capaz de atingir aos ideais de formação pessoal e social.

A greve dos professores, que completa hoje 73 dias, serviu para demonstrar que, também no que diz respeito ao ensino, a comunidade é altamente mobilizável. Até por ter imposto aos pais de alunos uma preocupação real, essa greve - atinja ou não seus objetivos - já obteve um sucesso, que foi justamente tornar acessível e popular o debate sobre o ensino público.

Quase sempre restrito às chamadas elites culturais (professores, universitários, sociólogos, etc.), esse debate ganhou vida e força nas últimas semanas, levando cada pessoa a refletir mais profundamente sobre a escola pública, posicionando-se sobre o assunto. Na imprensa, poucos temas tiraram das pessoas tantas e tão variadas manifestações de opinião. Grupos de pais decidiram reforçar os protestos dos professores, fazendo coro com suas reivindicações, enquanto outros preferiram condenar a greve e pedir a volta às aulas.

Já que a greve, em si, provocou tamanha mobilização na sociedade como um todo, seria interessante, também, que o debate não se esgotasse com o eventual retorno às atividades escolares. Contatada a realidade, que é das mais deprimentes, seria absurdo que os pais de alunos, bem como os alunos, retornassem à aparente normalidade dos dias de aula sem tentar, pelo menos, avançar o debate em favor deles próprios, procurando detectar os muitos defeitos do ensino que se oferece na rede estadual e pressionando pela sua melhoria. (A HORA DO ENSINO, 1989, p. 02). 
Como resultado na ação docente, essas greves deram maior visão de mundo para os professores, possibilitando-os discutir em salas de aulas questões mais amplas, relacionadas a políticas salariais do país, organização dos trabalhadores, democracia na escola e na sociedade.

Apenas a mais ampla das concepções de educação nos pode ajudar a perseguir o objetivo de uma mudança verdadeiramente radical, proporcionando instrumentos de pressão que rompam a lógica mistificadora do capital. Essa maneira de abordar o assunto é, de fato, tanto a esperança como a garantia de um possível êxito. (MÉSZÁROS, 2008, p. 48).

Embora tivessem como ponto principal a questão salarial, servia como aprendizado e superação de medos e, participação em acontecimento democrático.

A greve apresenta um conteúdo de aprendizagem, um processo em que a informação e o conhecimento aparecem como elementos de construção de uma relação de confiança entre os professores da escola e também entre estes e a direção do movimento grevista. $\mathrm{O}$ medo e a insegurança que acompanham qualquer trabalhador no momento de tomar a decisão sobre a adesão ou não à greve, também são sentidos pelos professores. (SOUZA, 1996, p. 148).

Muitos professores tinham a consciência de que a greve da categoria por si só já era uma vitória, ao mostrar para a sociedade os problemas da educação pública e também suas condições de trabalho. No momento em que a sociedade caminhava rumo a uma democracia e modernização, graças aos avanços tecnológicos, a educação estava retrocedendo.

Mas como conseguir o objetivo constitucional expresso no artigo $205 \mathrm{com}$ a real situação da escola pública? Os problemas eram tantos, que jogar a culpa só nos professores acusando-os de despreparados e corporativistas, tentando desqualificar suas greves não tinha sentido. O problema exigiu ampla abordagem social por parte daqueles que se propunham a analisá-lo. Para os pensadores de esquerda, críticos do capitalismo e comprometidos com ideais voltados ao socialismo, essa crise na educação era inerente ao sistema capitalista, que queria perpetuar a dominação sobre as classes trabalhadoras, não possibilitando sua emancipação através de uma educação de qualidade. O acúmulo de problemas só podia ser explicado dessa forma.

O quadro a que está reduzida a escola pública é melancólico: desinteresse dos governos, professores mal remunerados, despreparados, desanimados; crianças famintas, precocemente envolvidas no trabalho ou na marginalidade, empobrecidas culturalmente face às suas condições de vida, prejudicadas escolarmente por uma escola inadequada; escolas sujas, vidros quebrados, falta de recursos didáticos etc. Ou seja, os governos estão deixando que a escola permaneça numa agonia sem fim, não para matá-la, mas para mantê-la dentro dos limites mínimos de sobrevivência, tal como vem fazendo com o povo. Não está nos planos dos governos a elevação da qualidade da escola, porque não interessa à classe dominante a formação cultural verdadeira que libertaria os indivíduos e possibilitaria a tomada de consciência dos mecanismos de dominação capitalista. (LIBÂNEO, 2002, p. 80). 
A organização dos professores nesse período foi marcada pela luta de reivindicações de melhoria salarial e também pela cobrança de uma escola pública capaz de atender a todos com qualidade. Paradoxalmente, quando as autoridades políticas falavam em uma escola para atender a todos, o que se via era uma escola pública carente de recursos, com limites pedagógicos e até físicos. Nas reivindicações sempre constava a cobrança pela melhoria da escola pública.

A organização dos educadores na referida década pode, então, ser caracterizada por meio de dois vetores distintos: aquele caracterizado pela preocupação com o significado social e político da educação, do qual decorre a busca de uma escola pública de qualidade, aberta a toda a população e voltada precipuamente para as necessidades da maioria, isto é, a classe trabalhadora; e outro marcado pela preocupação com o aspecto econômico-corporativo, portanto, de caráter reivindicativo, cuja expressão mais saliente é dada pelo fenômeno das greves [...]. (SAVIANI, 2010, p. 404).

Apesar dessas manifestações, e da organização dos professores em torno de sua entidade representativa, a APEOESP e os professores continuaram alheios a políticas educacionais e pedagógicas elaboradas pelos representantes do estado, e dirigidas aos professores para que esses simplesmente a cumprissem. Já no início da década de 1980, surgiram iniciativas governamentais no sentido de revisão e reformas curriculares.

No início dessa década, a CENP (Coordenadoria de Estudos e Normas Pedagógicas) continuou a executar o projeto de elaboração dos "Subsídios para a implantação dos guias curriculares". Os subsídios foram elaborados com uma linguagem bem coloquial, pois apresentaramse sob a forma de manuais para o professor, como um "receituário", indicando a distribuição do conteúdo, do tempo, a avaliação e até palavras que o professor deveria usar. Era enorme, portanto, o grau de detalhamento e especificação, buscando direcionar e controlar a prática docente. (GARROSSINO, 2007, p. 16).

Essa política educacional implantada pelo estado reduzia a autonomia do professor em sala de aula, com seu trabalho orientado por teorias vindas de fora da prática docente cotidiana, e muitas vezes, sem mesmo até perceber, transmitindo a ideologia dominante, representada pelas diretrizes impostas pelo Estado.

Um dos aspectos decisivos do processo de redução da autonomia do trabalho docente na rede pública do estado de São Paulo é o fato de que a produção teórica que orienta este trabalho ocorre quase que invariavelmente fora da prática docente cotidiana, pelo menos em nível do trabalho docente na escola básica. Na condição de trabalhador o professor acaba aceitando esta pseudoteoria sem se aperceber muitas vezes que se transformou em um "hospedeiro da ideologia dominante". Este fenômeno leva a uma falsa expectativa de que a teoria que é produzida no exterior da prática docente possa dar conta dos problemas concretos da prática educativa cotidiana. (NOTÁRIO, 2007, p. 88-9). 
Durante a década de 1980, e apesar da continuidade político-partidária, a Secretaria de Educação do Estado de São Paulo enfrentou dificuldades na condução do sistema de ensino.

Passaram pelo governo do Estado de São Paulo, no período de 1983 a 1990, dois governadores do mesmo partido político, Partido do Movimento Democrático Brasileiro (PMDB). Esse poderia ser um fator positivo para a continuidade das políticas educacionais implantadas no Estado de São Paulo, entretanto, a administração da Secretaria Estadual da Educação, nesse período, passou por sete secretários, comprometendo, dessa forma, a continuidade administrativa e as políticas educacionais. (CASADO, 2006, p. 54).

Por meio da APEOESP, os professores se organizavam para combater a política educacional do estado e pressionar o governo a atender suas reivindicações. Internamente caminhavam para uma grande divergência, com formação de várias correntes políticas, cuja ideologia teórica e métodos de organização eram conflitantes.

Durante a década de 80 os Congressos Estaduais foram momentos privilegiados para a avaliação e formulação de propostas do sindicato às políticas governamentais em todas as esferas, porém, com o afastamento do sindicato da base da categoria, sobretudo com o aprofundamento do sindicalismo de massa que privilegiou, sobretudo após 1986, a luta salarial e a estratégia de mobilização da categoria como grupo de pressão, fez com que os Congressos se tornassem arena de conflitos viscerais entre as correntes sindicais atuantes na APEOESP.

Assim, os Congressos Estaduais, tornaram-se momentos de debate e disputa de projetos de sociedade, de sindicato, de luta, entre militantes. Este fator é importante, pois condiciona a formulação dos textos-tese apresentados aos congressistas. (GOULART, 2004, p. 165).

Apesar das divergências entre as correntes internas, as resoluções dos Congressos apresentavam propostas tidas como de esquerda ou no mínimo de centro-esquerda, marcando oposição ao governo em vários aspectos, e dessa forma, colocando a APEOESP na luta por mudanças sociais amplas, não se limitando apenas a questões corporativas. Como exemplo dessa postura, temos a resolução do $6^{\circ}$ Congresso Estadual da APEOESP, que aconteceu em outubro de 1985, na Cidade de Bauru, interior do Estado de São Paulo, e que tratava da questão da dívida externa do país e da relação com o Fundo Monetário Internacional (FMI), da seguinte forma:

A APEOESP deve se posicionar pelo não pagamento da dívida externa, mas deve assumir a posição da Conferência Sindical Latino-Americana e Caribenha contra a dívida externa e rompimento com o FMI, em uma grande articulação intersindical e popular supra-partidária; organizar um grande movimento que cobre e dê sustentação a uma nova política econômica contra a dívida externa, que rompa com o FMI.

Encaminhamentos: elaborar um documento com linguagem popular sobre o tema da Dívida Externa para os professores utilizarem em sala de aula. (VI CONGRESSO, 1985, p. 07). 
Nesse mesmo Congresso, foi aprovada uma posição sobre a Reforma Agrária, em oposição ao projeto do Governo Sarney.

A APEOESP, ao lado da CUT e do Movimento Popular, deve manifestar a sua oposição ao projeto demagógico de Reforma Agrária do Governo Sarney e insistir na luta por uma nova política agrícola e por uma Reforma Agrária radical, sob controle dos trabalhadores, não incluindo na distribuição as terras que representam os interesses de vida, sobrevivência e cultura dos povos indígenas (alertando para a necessidade imediata de ampliação das terras demarcadas).

Encaminhamento: a APEOESP deve fornecer subsídios e promover debates sobre a Reforma Agrária, e participar da Campanha Nacional pela Reforma Agrária. (VI CONGRESSO, 1985, p. 07).

O posicionamento da APEOESP era divulgado nas escolas, através de debates organizados por seus militantes e em formas de materiais impressos para serem trabalhados com os alunos (VI CONGRESSO). A prática tinha como base a ideia de que a escola é um espaço onde também acontece a luta de classes, mesmo que a comunidade escolar não tenha consciência disso.

O espaço escolar é um espaço de interesses distintos de classe: é um espaço de lutas de classes, pois, mesmo que os professores não tenham consciência de sua condição de classe, ele está submetido objetivamente às necessidades de reprodução ampliada do capital. Mesmo não produzindo diretamente mais-valia o professor contribui para a formação da força de trabalho desenvolvida no interior das escolas que vai ser explorada nos diversos setores da economia. (NOTÁRIO, 2007, p. 103).

Outra questão importante a ser destacada é que mesmo a APEOESP sendo a entidade oficial representativa dos professores, suas posições não eram aceitas por toda a categoria, pois muitos profissionais permanecem alheios às discussões que aconteciam no âmbito da entidade, e muitos sequer concordavam com sua prática. Mesmo nos momentos de luta, como nas greves, muitos professores não aderiam ao movimento por postura contrária à prática ou por divergirem do movimento sindical.

No âmbito da APEOESP, e como fator de luta interna, alguns grupos consideravam que a entidade precisava passar por um processo de democratização, superando a divisão entre os que dirigiam a entidade e os grupos de oposição, para que ela pudesse ter uma prática sindical unitária, e dessa forma atingir os interesses dos professores. A tese "Por uma APEOESP unitária, democrática e de lutas" apresentada no XIII Congresso da entidade, em agosto de 1994, chamava a atenção para esse ponto.

Consideramos extremamente importante construir uma prática sindical que busque a ampla unidade e democracia da categoria. Essa é a única forma de forjarmos a força necessária para lutarmos pelas nossas reivindicações. Infelizmente a prática hoje instalada na APEOESP divide artificialmente a categoria impondo um muro entre aqueles alinhados à "diretoria" e aqueles alinhados ao "movimento de oposição", criando um ambiente de patrulhamento político, sectarismo e divisão que prejudica a ampliação e fortalecimento do sindicato, impedindo na prática o livre debate de idéias e o diálogo entre as diferenças. Por isso, um dos nossos 
principais objetivos é construir uma prática sindical unitária, democrática e ligada aos interesses do conjunto dos professores. (TESES, 1994, p. $15)$.

Em 1995, assumiu o governo do estado de São Paulo, Mário Covas Júnior, do Partido Social Democrata Brasileiro (PSDB). Em sintonia com o governo federal, direcionou sua política pelos princípios neoliberais. Pautou sua política educacional por uma melhor "otimização" dos gastos, alegando que um dos maiores problemas da escola pública estava no péssimo gerenciamento dos recursos, e que o setor não precisava mais de investimentos, e sim, de fazer bom uso dos recursos existentes. Mesmo para a questão da correção dos salários dos professores, que também em sua avaliação eram baixos, seria necessária apenas uma "adequação" de recursos.

Parece-nos que o tema central na agenda do governo estadual a partir de 1995 é o de como gerir os recursos que estavam sendo mal gastos, desperdiçados, segundo suas avaliações. Afirma-se que o grave problema dos baixos salários dos profissionais nunca seria resolvido sem que se encontrassem formas de liberar recursos dentro do próprio sistema, já que o Estado não via como possível aumentar investimentos no setor. Este eixo, que viria a ser o articulador de quase todas as medidas implementadas a partir de 1995, foi duramente criticado pelos que identificavam aí a adequação da política educacional às orientações neoliberais, que objetiva um Estado mínimo. Os discursos de que a educação vai mal porque se gasta mal seus recursos, estaria, segundo os críticos ao governo, servindo para justificar o "enxugamento" e esvaziamento das funções sociais do Estado. (OLIVEIRA, 1999, p. 29, aspas no original).

Logo no início de seu governo foram divulgadas as Diretrizes Educacionais para o triênio de 1995 a 1998, que reconhecia os graves problemas, acumulados pela ineficiência das administrações anteriores, e que tornava a situação incompatível com o estado paulista industrializado e moderno e que precisava contar com uma boa estrutura pública na área da educação.

As últimas administrações não demonstraram sensibilidade aos problemas que São Paulo teria de enfrentar. Para atender adequadamente às demandas de um Estado com um perfil moderno, industrializado, ágil na absorção dos novos modelos de produção e das novas tecnologias, as últimas administrações deveriam ter investido maciçamente num sistema de prestação de serviços públicos moderno, racional, bem equipado, eficiente e bem remunerado, de modo a atrair profissionais capacitados e comprometidos com a prestação de um serviço de boa qualidade, notadamente no que se refere aqueles do setor educacional. (DIRETRIZES, 1995, p. 08).

Para resolver o problema e dar outro direcionamento à educação pública, as Diretrizes Educacionais colocavam como prioridade modernizar a Secretaria da Educação, tornando-a ágil, eficiente, moderna e flexível. Um discurso em moda pelos neoliberais.

Buscar-se-á construir na Secretaria uma máquina administrativa leve, ágil, flexível, eficiente e moderna, capaz de ser um instrumento eficaz na 
implantação de uma nova política educacional. Para tanto, dois objetivos deverão ser atingidos: a instituição de um sistema eficaz de informatização dos dados educacionais e a desconcentração e descentralização de recursos e competências. (DIRETRIZES, 1995, p. 09).

As Diretrizes expressavam reconhecimento pelo profissional da educação, prometendo valorização e estímulo ao trabalho docente, para que houvesse uma verdadeira revolução no ensino público paulista.

Nesta administração, o profissional da educação será respeitado, reconhecido e estimulado, pois, estando na ponta da sala de aula, torna-se o responsável pelo sucesso ou fracasso de qualquer política educacional de melhoria da qualidade do ensino. Com um profissional desencantado, desacreditado e desconfiado não há possibilidade alguma de se fazer uma revolução no campo da Educação, capaz de virar a educação paulista pelo avesso e dar a São Paulo um sistema de ensino à altura dos padrões de desenvolvimento do Estado mais rico da Federação. (DIRETRIZES, 1995, p. 10).

A questão da valorização dos professores, mediante melhorias salariais e melhores condições de trabalho se constituíra em antiga reivindicação dos docentes, cujos principais aspectos constavam na tese da diretoria da APEOESP, elaborada para o XIII Congresso estadual da entidade, a ser realizado em agosto de 1994, na cidade de Araçatuba, interior de São Paulo.

Piso do DIEESE;

Reposição das perdas salariais dos governos Quércia e Fleury - 201,36\% é o reajuste necessário;

Cumprimento do Orçamento do Estado: $30 \%$ do ICMS para o Ensino de $1^{\circ}$ e $2^{\circ}$ graus, sendo $23 \%$ para salários.

Gratificação do Trabalho Noturno (GTN) de 50\%;

Direito de optar pelo Regime de Dedicação Plena e Exclusiva (RDPE) para todos os professores;

Incorporação de todas as gratificações para efeito de aposentadoria, inclusive para os atuais aposentados;

Pagamento no último dia útil do mês;

Pagamento integral de 1/3 das férias;

Pagamento de vencimentos atrasados corrigidos conforme artigo 116 da Constituição Estadual;

Vale-alimentação equivalente ao das estatais;

Agilidade na implantação do convênio IAMSPE/hospitais particulares, em todo o Estado.

Limite máximo de 35 alunos no Ensino Fundamental $\left(5^{\mathrm{a}}\right.$ a $8^{\mathrm{a}}$ série $)$ e $2^{\mathrm{o}}$ grau e 30 alunos nas salas de $1^{\text {a }}$ a $4^{\mathrm{a}}$ série;

[...]. (TESES, 1994, p. 05).

Dessa forma, o governo Covas tinha na área da educação um desafio. Ao reconhecer a calamidade em que a situação se encontrava e propor uma "revolução" para o setor, deparava-se com antigas reivindicações dos professores, que no decorrer do mandato governamental foram se tornando incompatíveis com sua política educacional. No XIV 
Congresso Estadual da APEOESP, realizado em outubro de 1995, foram aprovadas resoluções com críticas à sua política para com a educação.

Ao enviar à Assembléia Legislativa a primeira proposta orçamentária de seu governo, o governador Mário Covas registra austeridade, e o corte afiado se volta principalmente para Educação. Se votada desta maneira, transformando-se no Orçamento, nunca se terá destinado no ensino fundamental e médio uma fatia tão pequena dos recursos públicos. Uma maneira de ilustrar isso talvez seja comparar o gasto médio no período de $79 / 94$ com que se pretende fazer o ano que vem. No ensino de $1^{\circ}$ grau, os três últimos governos gastaram, em média, o equivalente a $22,7 \%$ da arrecadação do ICM/ICMS. Para 1996 Covas propõe gastar 17,1\%. O $2^{\circ}$ grau sofrerá corte equivalente. A média foi $1,6 \%$ e o previsto para o próximo ano é de $1,1 \%$. Com os salários da Secretaria de Educação, ao longo dos últimos 16 anos se gastou uma média de 19,6\% da arrecadação do principal imposto estadual. A previsão para o próximo ano é de $14,1 \%$. Praticamente o mesmo percentual que se aplica hoje. (CONSTRUINDO..., 1995, p. 06).

Nesse mesmo Congresso, evidenciou-se o descontentamento da APEOESP para com o governo de Mário Covas.

Passados dez meses do início do governo Mário Covas, seu Programa de Educação não foi discutido com a sociedade e sequer foram consideradas as opiniões expressas pela comunidade escolar a seu respeito. Eleito com um discurso em que afirmava o compromisso de colocar o salário dos professores num piso de 5 mínimos por 20 horas/aulas, Covas aplica o Plano Decenal em São Paulo com o argumento de que o Estado não tem dinheiro e que a arrecadação caiu, por isso parcelou e pagou atrasado o salário, acabou com a segurança escolar, não cumpre o orçamento, lança a lei complementar (794/95), que estimula a demissão voluntária, contribuindo com o êxodo dos profissionais da Educação, anuncia a demissão de sessenta mil professores e milhares de funcionários públicos. (CONSTRUINDO..., 1995, p. 08).

Diante dessas divergências, o Congresso da APEOESP aprovou os principais pontos para embasar as lutas dos professores e combater a política do governo Mário Covas. Conforme Resolução aprovada no XIV Congresso, a APEOESP lutaria por:

Criação de um fórum permanente de discussão dos projetos da SE;

Revogação imediata das demissões de professores e funcionários;

Revogação imediata do decreto de faltas;

Suspensão do projeto de reestruturação da rede;

Não implantação do projeto de municipalização do ensino;

Não implantação do projeto de parcerias com a iniciativa privada;

Rejeição total do projeto de reformas do ensino básico de Covas;

Fim das perseguições políticas do governo Mário Covas aos trabalhadores em Educação. (CONSTRUINDO..., 1995, p. 09)

O governo tratou a APEOESP com autoritarismo, mantendo uma posição inflexível durante as negociações com o sindicato, e procurou desqualificá-la como representante dos professores. Além de tomar medidas relacionadas a área da educação sem ouvir os 
professores, através da entidade sindical, usou a imprensa para divulgar tais medidas, numa demonstração de desprezo pela APEOESP. Também tentou enfraquecê-la, dificultando a participação dos professores nas atividades promovidas pelo sindicato.

Deve-se salientar que a SEE e o governo buscaram desestruturar o sindicato e enfraquecê-lo frente à comunidade escolar e à população em geral. $\mathrm{O}$ governo permaneceu inflexível às negociações com o sindicato durante toda a gestão. Não foi incomum a SEE utilizar-se da imprensa para informar importantes medidas que interferiam na vida escolar, anulando a APEOESP como interlocutora da categoria. Além disso, desferiu ações que atingiram as bases de organização do sindicato. Conquista da APEOESP durante o governo Montoro, a participação dos professores em atividades sindicais como encontros, seminários, reuniões de representantes de escola, eleições do sindicato, entre outras, não constavam como faltas. Em 1996, a SEE nega o abono de ponto aos professores durante as eleições gerais da entidade, que ocorreriam, desde então, com urnas volantes. (GOULART, 2004, p. 174).

Além das discordâncias com as políticas educacionais, havia também divergências entre concepção de educação que deveria embasar a escola pública. O governo defendia um ensino que preparasse as novas gerações para a economia capitalista, formando cidadãos capazes de se adaptarem às mudanças do processo produtivo capitalista, que estava em processo de crescente internacionalização.

O profundo avanço tecnológico dos anos 80, o impacto da informatização e o processo crescente de internacionalização da economia estão, naturalmente, a exigir um novo perfil de cidadão: criativo, inteligente, capaz de solucionar problemas, de se adaptar às mudanças do processo produtivo e, principalmente, de gerar, selecionar e interpretar informações. Nesse cenário, a Educação torna-se, mais do que nunca, indispensável ao sucesso econômico e social de qualquer país que se proponha a enfrentar a competição internacional. Consequentemente, passa-se a questionar os sistemas de ensino e a exigir ousadia para revêlos e modificá-los. (DIRETRIZES, 1995, p. 08).

O sindicato dos professores, por sua vez, defendia uma educação valorizadora da cultura popular, do pluralismo de ideias e voltada para a transformação social. A escola deveria estar a serviço da comunidade, e o ensino privilegiar a formação da consciência crítica, e não simplesmente a formação para se adequar, se adaptar às inovações do sistema capitalista. A educação teria que ser um instrumento de luta em favor da liberdade, visando a uma transformação da sociedade.

Em nossa concepção, a Escola Pública para o trabalhador deverá ser alegre, competente, séria, democrática e, sobretudo, comprometida com a transformação social, gratuita em todos os níveis e para todos. Deverá vir a ser uma escola mobilizadora, a serviço da comunidade, centro irradiador da cultura popular, capaz de recriá-la, permanentemente.

Deverá ser unitária na qualidade e no desenvolvimento de um projeto educacional e de um processo pedagógico que tenha o trabalho como princípio educativo, não no sentido de Escola uniformizadora, formadora de cabeças em série, e sim um espaço sadio de pluralismo de idéias. $\mathrm{O}$ saber adquirido na Escola, imprescindível para o cumprimento de suas 
finalidades, não será visto como um fim em si mesmo - mas como um instrumento de luta. Em nossa concepção, o fim da Educação é a formação da consciência crítica, predominando a idéia de liberdade. (RESOLUÇÃO..., 1991, p. 02).

Coerente com sua concepção de educação, a APEOESP tomou a iniciativa de organizar cursos e atividades educativas entre os professores, para que estes pudessem estar discutindo democraticamente sobre qual educação interessa para a maioria da população. De acordo com a APEOESP, essa prática melhoraria a formação profissional dos docentes em todos os sentidos e caminharia no sentido de democratizar a escola pública, normalmente tratada de forma autoritária, recebendo os projetos educacionais do governo de forma vertical, sem discussão com os docentes.

A partir de 1982, a APEOESP assumiu a iniciativa da organização de Congressos de Educação, Encontros por Área, Cursos para professores, mostras de Teatro, consciente de que a melhoria da qualidade do ensino se tornará real se, junto com a luta por melhores salários e condições de vida e trabalho, houver a participação organizada do professorado na transformação da escola e da educação. Foi com este objetivo que nos colocamos em movimento, criando espaços de discussão, onde os professores pudessem, democraticamente decidir qual educação interessa à maioria da população. Entendemos que é só desta forma, com a participação de todos os envolvidos no processo educativo, que a educação deixará de ser decidida por poucos, e que, por mais progressistas que sejam suas propostas, será tão autoritária como o foram muitos dos projetos educacionais, leis, etc, implantados no país até hoje.

A prática tem demonstrado que os professores só incorporam as mudanças quando participam da sua elaboração. Agindo desta forma, a APEOESP tem obtido vitórias significativas nos últimos anos. Milhares de professores têm participado deste movimento, refletindo e debatendo sobre a sua formação profissional, política e sindical, os conteúdos, a democratização da educação, etc. Temos a certeza absoluta que os professores que têm participado deste movimento, vêm tendo uma prática, na escola e principalmente na sala de aula, consequiente e questionadora dos conteúdos impostos pelo livro didático e outras formas de dominação existente dentro da unidade escolar. Este movimento vem tendo uma participação decisiva na democratização da escola. (A APEOESP, 1988, p. A-3).

Mas a formação profissional dos professores estava bastante fragilizada, e também era motivo de críticas que os responsabilizavam pelo insatisfatório desempenho da escola pública, tanto por parte do governo, que ciente da situação da educação pública, atribuía a culpa pelo fraco preparo profissional dos docentes, como por intelectuais, que ao analisar o "caos" em que se encontrava a educação, via uma parcela de culpa na formação dos professores. Em artigo publicado no jornal Folha de São Paulo, em dezembro de 1997, o historiador Jaime Pinsky, ao cobrar mudanças radicais para a educação pública, fez uma análise do perfil profissional do professor da escola pública.

Jogados diante dos alunos da rede pública, muitos professores são incapazes de operacionalizar conceitos básicos de suas áreas, não conseguem construir um conhecimento junto com o aluno e logo entram no ramerrão dos conhecimentos prontos e acabados. Usando o livro 
didático não como componente do seu arsenal pedagógico, mas como bengala para suas deficiências, vários estudam com o material que deveria servir para ensinar. Muitas vezes, um livro didático é o único que tanto os alunos como o professor consultaram. (PINSKY, 1997, A-3).

A APEOESP estava ciente dessa carência de formação do professor, e além das atividades educacionais e cursos elaborados visando contribuir para a superação desse problema, cobrava do governo condições para atualização profissional dos professores. A tese "Em defesa do salário e da escola pública", apresentada no XIII Congresso da entidade, reivindicava que a cada ano trabalhado pelo professor, o Estado concedesse um mês de afastamento remunerado, para o docente realizar cursos nas universidades públicas.

A formação dos trabalhadores em educação só não é melhor porque não temos tempo para nos atualizarmos, portanto, a medida necessária, além das que já apontamos anteriormente, é que todos os profissionais tenham um período exclusivo, remunerado pelo Estado, para seu estudo e aperfeiçoamento. Para isso, é preciso reivindicarmos que: a cada ano trabalhado, haja 1 mês de afastamento remunerado para realização de cursos de atualização nas universidades públicas. (TESES, 1994, p. 27).

As razões foram dificultosas para fazer da escola um espaço democrático capaz de atender a todos, e solucionar, democraticamente, os conflitos cotidianos.

Os decretos e determinações pedagógicas foram baixados pelo estado, sem a participação da categoria em sua elaboração. Muitos diretores e professores atuavam com posturas autoritárias no exercício de suas profissões, reproduzindo no exercício de suas atividades a formação que tiveram, e consideram o direito dado aos alunos como se fosse a perda de sua autoridade. Para esses profissionais era difícil conciliar sua autonomia profissional com a liberdade dos alunos, garantida pelo estado de direito. Mas por outro lado, as experiências vividas por esses profissionais, inclusive as greves, deveriam ter dado condições de superarem a formação autoritária que tiveram e adquirir postura democrática, importante para que a ação docente pudesse ser ampla e de qualidade.

A ação docente na perspectiva democrática deve ser entendida como a relação estabelecida entre o professor e os alunos, e a postura do professor dentro e fora da sala de aula, ao se posicionar politicamente diante de acontecimentos sociais que envolvem desde sua condição de trabalho a políticas de maior amplitude, e que se relacionam com a realidade dos alunos.

É certo que a sala de aula representa o principal espaço de atuação dos professores, mas a prática docente não acontece apenas ali. Ressalta-se, assim, a importância de compreender as ligações do espaço escolar com o sistema de ensino e com o sistema social, para articular as práticas pedagógico-didáticas com as demais práticas sociais concorrentes. (LIBÂNEO, 2003, p. 38).

A título de considerações finais, cabe salientar que não adianta o professor reclamar de suas condições de trabalho e não lutar para melhorá-las. Sua ação docente tem que ser crítica e comprometida com a transformação social, não limitando a trabalhar com seus alunos apenas os conteúdos de sua matéria. Conforme Libâneo (2003, p. 32), "[...] é preciso que enxergue mais longe, para tomar consciência das intenções do sistema escolar na conformação de sujeitos-professores e de sujeitos-alunos". É necessário denunciar as 
injustiças sociais e apontar caminhos, através do diálogo e de sua prática política, em busca da transformação social.

Um projeto educacional autêntico, comprometido com a escolarização de todos com qualidade, no contexto adverso da sociedade brasileira atual, adquire, necessariamente, um caráter contra-ideológico de conteúdo humanista, de denúncia e desmascaramento do projeto político vigente. E é na ação dos professores que atuam em consonância com suas diretrizes, que ele vai ampliando sua base de apoio. Esse é um dos lados do trabalho do educador: de posse de seu saber, atuando para produzir conhecimento de forma crítica, competente e criativa, ele amplia seu espaço de ação e vai desenvolvendo uma atuação política comprometida com a transformação social em favor da maioria excluída. (CONSTRUINDO..., 1995, p. 03).

Nesse sentido, as greves protagonizadas pelos professores da rede pública do Estado de São Paulo demonstraram que os trabalhadores devem participar ativamente da luta por melhores condições de trabalho e de vida, intervindo para mudar a realidade, e não apenas se incorporando ao mercado de trabalho. É a efetivação da ação docente fora da sala de aula, mostrando aos alunos que estes devem ser cidadãos críticos, participando das decisões importantes para transformar a realidade em que vivem. Isso é função da escola, que deve investir para a formação da cidadania crítica e participativa.

A formação para a cidadania crítica e participativa diz respeito a cidadãos-trabalhadores capazes de interferir criticamente na realidade para transformá-la, e não apenas para integrar o mercado de trabalho. A escola deve continuar investindo para que se tornem críticos e se engajem na luta pela justiça social. Deve ainda entender que cabe aos alunos se empenhar, como cidadãos críticos, na mudança da realidade em que vivem e no processo de desenvolvimento nacional e que é função da escola capacitá-los para que desempenhem esse papel. (LIBÂNEO, 2003, p. 119).

Quando os professores se organizam e reivindicam direitos, como melhores salários e condições dignas de trabalho, estão exercendo a cidadania crítica, pois além de suas exigências, mostram para a sociedade um problema maior e que diz respeito a todos, que são as condições em que se está dando a formação das gerações futuras. O fato de se ter uma entidade sindical representando a categoria, mostra como os trabalhadores devem se organizar e tem sua ação pedagógica. Mas além da luta política, é importante o envolvimento dos docentes com o seu sindicato, buscando aperfeiçoamento e dignidade profissional. Isso reflete em melhor qualidade do trabalho do professor em sala de aula, e sua capacidade de organização e luta deve servir como exemplo de cidadania para seus alunos.

É preciso resgatar a profissionalidade do professor, reconfigurar as características de sua profissão na busca da identidade profissional. É preciso fortalecer as lutas sindicais por salários dignos e condições de trabalho. É preciso, junto com isso, ampliar o leque de ação dos sindicatos envolvendo também a luta por uma formação de qualidade, de modo que a profissão ganhe mais credibilidade e dignidade profissional. (LIBÂNEO, 2001, p. 10-1). 
O envolvimento do sindicato dos professores com questões sociais amplas, opinando sobre assuntos políticos que envolvem a sociedade, contribui para a transformação social. E a participação dos professores nessas discussões no âmbito do sindicato, na escola junto com o corpo docente, alunos e comunidade escolar, atua no fortalecimento dos movimentos sociais, e enriquece a ação docente, pois aquilo que a escola deve esperar dos alunos, ou seja, a formação de uma cidadania crítica e participativa, é vivenciada pelos professores. De acordo com Libâneo (2001, p. 09) "[...] a escola tem um grande papel no fortalecimento da sociedade civil, das entidades, das organizações e movimentos sociais. Ora, tudo o que esperamos da escola para os alunos são, também, exigências colocadas aos professores."

Para a ação docente ser pautada em um projeto político de emancipação social, é preciso que ele entenda o que é estar engajado nos movimentos sociais, participe sindicalmente, demonstre para os alunos que sua prática condiz com seu discurso de transformação social, despertando a consciência coletiva dos educandos para a conquista da cidadania, que só acontecerá através das lutas sociais. Segundo Libâneo (2001, p. 09) "[...] o fortalecimento das lutas sociais, a conquista da cidadania, dependem de ampliar, cada vez mais, o número de pessoas que possam participar das decisões primordiais que dizem respeito aos seus interesses."

A escola representa o local em que se encontram as aspirações coletivas da sociedade e os projetos pessoais de alunos e professores. E para que a ação docente se torne de fato educacional, é necessário que ocorra a humanização. Respeito, solidariedade, amizade e conquista de direitos são fundamentais. Também as práticas políticas voltadas para a superação das desigualdades sociais despertam para a cidadania e enchem de sentido a ação docente.

[...] a escola se dá como lugar do entrecruzamento do projeto político coletivo da sociedade com os projetos pessoais e existenciais de educandos e educadores. É ela que viabiliza que as ações pedagógicas dos educadores se tornem educacionais, na medida em que as impregna das finalidades políticas da cidadania que interessa aos educandos. Se, de um lado, a sociedade precisa da ação dos educadores para a concretização de seus fins, de outro, os educadores precisam do dimensionamento político do projeto social para que sua ação tenha real significação enquanto mediação da humanização dos educandos. Estes encontram na escola um dos espaços privilegiados para a vivificação e efetivação de seu projeto. (SEVERINO, 1995, p. 16-7).

A relação entre Estado, escola, profissionais da educação e alunos passa a ser confusa. Em alguns aspectos ela se mantém autoritária, mas em outros aspectos existe a cobrança pela atuação democrática. Nesse contexto, ganham respaldo algumas propostas pedagógicas de cunho progressista.

Poucos negariam hoje que os processos educacionais e os processos sociais mais abrangentes de reprodução estão intimamente ligados. Consequentemente, uma reformulação significativa da educação é inconcebível sem a correspondente transformação do quadro social no qual as práticas educacionais da sociedade devem cumprir as suas vitais e historicamente importantes funções de mudança. Mas, sem um acordo 
sobre esse simples fato, os caminhos dividem-se nitidamente. Pois caso não se valorize um determinado modo de reprodução da sociedade como o necessário quadro de intercâmbio social, serão admitidos, em nome da reforma, apenas alguns ajustes menores em todos os âmbitos, incluindo o da educação. (MÉSZÁROS, 2008, p. 25).

Esse período analisado coincide com amplos debates políticos na sociedade brasileira; atuação de importantes movimentos sociais, representando avanços democráticos, e como não podia ser diferente, a questão da educação pública ocupa espaço privilegiado. Ao discutirmos questões relacionadas a políticas educacionais implantadas pelo Estado, atuação coletiva dos professores, representados pelo seu sindicato, podemos entender a sociedade passando por mudanças em seu aspecto estrutural e a questão da escola pública no centro do debate. Se a sociedade caminha rumo à democracia e ao desenvolvimento científico, a educação adquire maior valor. Mas para sua concretização, é necessário o debate e a participação de todos os envolvidos. A atuação do movimento sindical em defesa da categoria docente e da escola pública torna-se fundamental.

\section{Referências}

APEOESP EM NOTÍCIAS: A APEOESP e a Formação do Educador, São Paulo, SP, no 154, p. 08, dezembro 1988.

Resoluções do Congresso Estadual de Educação da APEOESP em 1991.

Suplemento de Educação. São Paulo, SP, nº 172, p. 02, maio/junho 1991.

. VI CONGRESSO Estadual Anual da APEOESP. Caderno de Resoluções. São Paulo, SP, p. 07, outubro 1985.

CASADO, Maria Inês Miquelato. O Sistema de Ciclos e a Jornada de Trabalho do Professor do Estado de São Paulo. 2006, 110 f. Dissertação (Mestrado em Educação) Faculdade de Ciências Humanas, Universidade Metodista de Piracicaba, UNIMEP, Piracicaba, SP.

CONSTRUINDO um projeto da APEOESP para a Escola. Resoluções Aprovadas no XIV Congresso Estadual de Educação. APEOESP, São Paulo, SP, 26 à 28 out. 1995.

CRUZEIRO DO SUL: A hora do ensino. Sorocaba, SP, ano 86, n 24.612, p.02, 01 julho 1989.

CRUZEIRO DO SUL: Magistério em Greve. Sorocaba, SP, ano 85, nº 24.555, p. 02, 25 abril 1989.

DIRETRIZES Educacionais para o Estado de São Paulo no período de 1995 a 1998. Comunicado Secretaria de Educação de 22 de março de 1995. Diário Oficial do Estado, São Paulo, 23 março 1995, Seção I, p. 08 a 10. Disponível em: <http://www.imprensaoficial.com.br > acesso em: 20/05/2011.

FERREIRA JR, Amarilio; BITTAR, Marisa. A Proletarização dos Professores. Educação e Sociedade, volume 27, nº 97, Set/Dez. 2006. Campina, SP. Disponível em: <HTTP://www.cedes.unicamp.br >. acesso em: 31/01/2011.

GARROSSINO, Silvia Regina Barbosa. A Contribuição de Dermeval Saviani no Conselho Estadual de Educação de São Paulo (1984-1987). 2007, 94 f. Dissertação (Mestrado em Educação) Faculdade de Filosofia e Ciências, Universidade Estadual Paulista, Marília, SP. GOULART, Débora Cristina. Entre a Denúncia e a Renúncia: “A APEOESP (Sindicato dos Professores do Ensino Oficial do Estado de São Paulo) Frente às Reformas na 
Educação Pública na Gestão Mário Covas (1995-1998)”. 2004, 226 f. Dissertação (Mestrado em Sociologia) Departamento de Sociologia do Instituto de Filosofia e Ciências Humanas, Universidade Estadual de Campinas, UNICAMP, Campinas, SP.

LIBÂNEO, José Carlos. Adeus Professor, Adeus Professora? Novas exigências educacionais e profissão docente. $5^{\mathrm{a}}$ ed. São Paulo, SP: Cortez, 2001.

Democratização da Escola Pública: A pedagogia crítico-social dos conteúdos, $18^{a}$ ed. São Paulo, SP: Edições Loyola, 2002.

OLIVEIRA, João Ferreira de; TOSCHI, Mirza Seabra. Educação Escolar: políticas, estrutura e organização. São Paulo, SP: Cortez, 2003.

MÉSZÁROS, István. Tradução de Isa Tavares. A Educação Para Além do Capital. $2^{\mathrm{a}}$ ed. São Paulo, SP: Boitempo, 2008.

NOTÁRIO, Antonio Carlos Soler. Autonomia do Trabalho Docente na Rede Pública Paulista: política educacional e resistência sindical. 2007, 137 f. Dissertação (Mestrado em Educação) Faculdade de Educação e Letras, Universidade Metodista de São Paulo, São Bernardo do Campo, SP.

OLIVEIRA, Sônia Regina Ferreira de. Formulação de Políticas Educacionais: Um estudo sobre a Secretaria de Educação do Estado de São Paulo (1995 - 1998). 1999, 43f.

Dissertação (Mestrado em Educação) Faculdade de Educação, Universidade Estadual de Campinas, UNICAMP, Campinas, SP.

PINSKY, Jaime. Um Choque Educacional Para o Brasil. Folha de São Paulo, São Paulo, SP, p. A-3, 17 dezembro 1997.

RIBEIRO, Maria Luísa Santos. A formação política do professor de $1^{o}$ e $2^{\circ}$ graus. São Paulo, SP: Cortez, 1987.

SAVIANI, Dermeval. História das Idéias Pedagógicas no Brasil, $3^{\circ}$ ed. Campinas, SP: Autores Associados, 2010.

SEVERINO, Antonio Joaquim. Da Escola Como Mediação Necessária do Necessário Projeto Educacional. Subsídios para os encontros Regionais. Preparatórios ao Congresso (Republicação). Resoluções do XIV Congresso Estadual de Educação. APEOESP. São Paulo, SP, p. 16-7, outubro 1995.

SOUZA, Aparecida Neri de. Sou Professor, Sim Senhor! representações do trabalho docente. Campinas, SP: Papirus, 1996.

TESES para o XIII Congresso da APEOESP. Caderno de Teses. Educação no Centro das Atenções: uma urgência nacional. São Paulo, SP, Agosto 1994.

\section{Notas}

\footnotetext{
${ }^{1}$ Mestre em Educação pelo Programa de Pós-Graduação em Educação da Universidade de Sorocaba. Docente do curso de Pedagogia da Universidade de Sorocaba e da rede Pública Estadual. prof_antoniodepadua@hotmail.com.br

${ }^{2}$ Doutora em Geografia Humana pela Universidade de São Paulo. Docente do Programa de Pós-Graduação (Mestrado e Doutorado) e do Curso de Pedagogia, da Universidade de Sorocaba.

vania.boschetti@prof.uniso.br

${ }^{3}$ Este artigo é um substrato da dissertação de Mestrado em Educação: "Ação docente em tempos de abertura: considerações sobre a história da educação pública paulista de 1985 a 2000”, de Antonio de Pádua Almeida, defendida em 2011, na Universidade de Sorocaba, UNISO.
} 


\begin{abstract}
${ }^{4}$ A APEOESP foi fundada em 1945, como associação dos professores, mas adquiriu caráter sindical a partir do final da década de 1970, quando parte dos professores passou a tê-la como referência e representação para a categoria, principalmente para os chamados professores III (aqueles que trabalhavam com alunos a partir da então $5^{\mathrm{a}}$ série e $2^{\mathrm{o}}$ grau).

${ }^{5}$ Discussão abordada em : "Docentes paulista e atuação política no período de democratização pós-ditadura militar", artigo publicado na Série-Estudos - Periódico do Programa de Pós-Graduação em Educação da Universidade Católica Dom Bosco, n.33 (jan/jun. 2012) Campo Grande, MS.
\end{abstract}

Recebido em

abril-13

Aprovado em

novembro-13 